\title{
PENGARUH KOMPETENSI, OBJEKTIVITAS, DAN TEKANAN ANGGARAN WAKTU TERHADAP KUALITAS HASIL AUDIT PERWAKILAN BPKP SULAWESI UTARA
}

\author{
Hans Lohonauman ${ }^{1}$, Jullie J. Sondakh ${ }^{2}$, Meily Y. B. Kalalo ${ }^{3}$ \\ 1,2,3 Jurusan Akuntansi, Fakultas Ekonomi dan Bisnis, Universitas Sam Ratulangi, Jl. Kampus Bahu, Manado, \\ 95115, Indonesia \\ E-mail : hanz.lohonauman@gmail.com
}

\begin{abstract}
This study aims to determine the influence of competence, objectivity, and time budget pressure on the quality of audit results BPKP North Sulawesi Representative. The population used in this study is the BPKP auditor. Method of sampling by purposive sampling according to predetermined criteria. The number of samples collected was 45 respondents. The research data is the primary data obtained directly from the research object. The collected data is analyzed by using data analysis which is done by testing the data quality and classical assumption before doing hypothesis testing. Hypothesis testing in this study using multiple linear regression analysis with $t$ test, $f$ test, and coefficient of determination. The results of this study indicate that the variables of competence and objectivity have a significant effect on the quality of audit results. This shows that competence and objectivity affect the quality of audit results. While the time budget pressure had no significant effect on the quality of audit result. This suggests that time budget pressure does not affect the quality of audit results.
\end{abstract} Keywords : competence, objectivity, time budget pressure, and quality of audit results

\section{PENDAHULUAN}

Setiap profesi harus menjaga martabat dan kualitas jasa profesionalnya dengan cara membangun kepercayaan. Membangun kepercayaan masyarakat dilakukan dengan perilaku para profesional harus diatur agar kualitas hasil pekerjaannya dapat dipertanggungjawabkan. Sehingga, standar dan aturan etika profesi diperlukan agar masyarakat dapat meyakini kualitas pekerjaannya. Suatu perusahaan memerlukan proses auditing dikarenakan dengan proses ini seorang akuntan dapat memberikan pernyataan pendapat atas kewajaran atau kelayakan laporan keuangan sesuai dengan standar audit yang berlaku umum. Audit adalah proses yang terstruktur yang dilakukan untuk menentukan tingkat kesesuaian antara pernyataan-pernyataan dengan standar yang ditetapkan, serta melaporkan hasilnya dari kegiatan dan kejadian ekonomi dengan menguji bukti secara objektif atas pernyataanpernyataan yang diberikan.

Auditor adalah orang yang punya peran penting untuk pengontrolan dan penjaga kepentingan publik dibidang yang terkait dengan keuangan. Auditor bertanggungjawab dalam membuat rencana serta melaksanakan audit untuk mendapatkan keyakinan dari laporan keuangan apakah telah tidak salah saji material yang diakibatkan karena kekeliruan atau kecurangan. Auditor yang bekerja untuk Badan Pengawasan Keuangan dan Pembangunan (BPKP) merupakan auditor internal pemerintah, yang memberikan layanan atas kebutuhan pemerintah. BPKP dikerakan untuk melakukan penilaian kembali dari efisiensi dan efektivitas berbagai program pemerintah. Dalam melaksanakan tugasnya, auditor tidak terlepas dari kendala-kendala yang dihadapi baik dari faktor internal maupun faktor eksternal yang dapat mempengaruhi kualitas hasil audit. Kualitas hasil audit dinilai dari banyaknya auditor yang meresponi dengan benar temuan pekerjaan audit yang telah diselesaikan. Kualitas hasil audit ditunjukan dengan laporan hasil pemeriksaan dapat diandalkan sesuai 
standar yang berlaku. Untuk menemukan pelanggaran auditor wajib memiliki kompetensi, kecermatan, serta kehati-hatian profesional. Kompetensi adalah pengetahuan dan keahlian yang diperlukan untuk mencapai yang menentukan pekerjaan individual.

Objektivitas adalah kualitas seorang internal auditor yang melibatkan eksistensi intelektual briliant, keadilan teladan dan bebas dari konflik penting. Auditor tidak boleh kompromi dengan pertimbangan profesionalnya karena adanya bias, konflik kepentingan atau karena adanya pengaruh dari orang lain yang tidak semestinya. Tekanan anggaran waktu merupakan keadaan yang mengharuskan auditor menggunakan waktu semaksimal mungkin dari waktu yang telah dianggarkan atau batasan waktu yang ketat dan kaku.

\section{TINJAUAN PUSTAKA}

Akuntansi. Akuntansi merupakan suatu seni pencatatan, pengklasifikasian, dan pengikhtisaran dalam cara yang signifikan atas transaksi-transaksi dan kejadian-kejadian yang memiliki sifat keuangan dan satuannya ialah mata uang.

Akuntansi Keuangan. Bidang akuntansi yang memberikan informasi akuntansi secara umum dan fokus utamanya bagi pihak eksternal untuk pengambilan keputusan merupakan kegiatan akuntansi keuangan. Yang dihasilkan akuntansi keuangan adalah informasi keuangan tentang sebuah entitas Martani (2012:8).

Audit. Penilaian kembali bukti atas informasi guna menetapkan dan memberikan laporan tingkat korespondensi informasi dan kriteria yang ditetapkan. Audit wajib dilakukan oleh orang yang kompeten dan independen (Arens et al., 2013:24).

\section{Jenis-Jenis Audit}

1. Audit Operasional (Operational Audit). Audit operasional menilai efisiensi dan efektivitas operasi organisasi apakah telah sesuai dengan standar yang berlaku.

2. Audit ketaatan (Complience Audit). Audit ketaatan dilaksanakan guna menentukan suatu organisasi telah mengikuti prosedur, aturan, atau ketentuan tertentu.

3. Audit Laporan Keuangan (Financial Statement Audit). Audit laporan keuangan menentukan semua laporan keuangan apakah sudah dilaporkan sesuai dengan standar yang berlaku.

Tujuan Audit. Institut Akuntan Publik Indonesia dalam Standar Profesional Akuntan Publik (2011:110.1) tujuan audit adalah memberikan pendapat berdasarkan standar akuntansi yang berlaku umum di Indonesia atas kewajaran, hal yang material, posisi keuangan, hasil usaha, perubahan atas ekuitas dan arus kas.

Standar Audit. Kriteria atau ukuran mutu pelaksanaan akuntan merupakan bagian dari Standar audit. Standar auditing yang telah ditetapkan dan disajikan oleh adalah sebagai berikut: (1) Standar Umum; (2) Standar Pekerja Lapangan; dan (3) Standar Pelaporan.

Kualitas Hasil Audit. De Angelo (1981) kualitas hasil audit merupakan kemungkinan auditor akan menemukan serta memberikan laporan atas pelanggaran dalam sistem akuntansi klien.

Kompetensi. Mulyadi (2013:58) kompetensi diukur dari adanya capaian dan tingkatan pemahaman serta pengetahuan yang bisa membuat seseorang untuk memberikan jasanya dengan kemudahan dan kecerdikan.

Objektivitas. Arens dan Loebbecke (2003) menyatakan keyakinan dan kualitas untuk melakukan jasa atau pelayanan auditor merupakan definisi dari objektivitas. Setiap auditor bekerja dengan kemampuan yang berbeda dan harus tetap mempertahan objektivitas mereka disituasi apapun (Mulyadi, 2014).

Tekanan Anggaran Waktu. Tekanan anggaran waktu merupakan kendala yang terjadi pada perjanjian audit dikarenakan adanya batasan atau pengalokasian sumber daya waktu dalam melaksanakan seluruh tugas audit (DeZoort dan Lord dalam Fonda, 2014). 


\section{Kerangka Pemikiran}

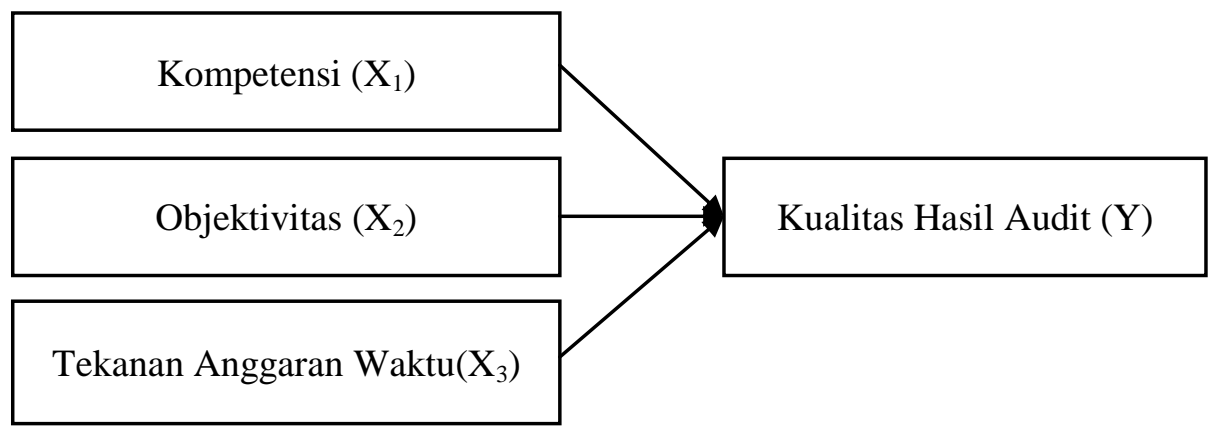

\section{Hipotesis Penelitian :}

$\mathrm{H}_{1}$ : Kompetensi berpengaruh signifikan terhadap kualitas hasil audit

$\mathrm{H}_{2}$ : Objektivitas berpengaruh signifikan terhadap kualitas hasil audit

$\mathrm{H}_{3}$ : Tekanan anggaran waktu berpengaruh terhadap kualitas hasil audit

\section{METODE PENELITIAN}

Jenis Penelitian. Jenis penelitian yang digunakan dalam penulisan skripsi ini adalah penelitian kuantitatif kausal. Penelitian kuantitaif, menganalisis data-data secara kuantitatif/statistik yang bertujuan menguji hipotesis yang telah ditetapkan serta menginterpretasikan hasil analisis tersebut guna memperoleh kesimpulan. Sedangkan, kausal, penelitian dengan tujuan untuk mengetahui pengaruh antar variabel.

Populasi dan Sampel. Populasi dalam penelitian ini adalah seluruh auditor BPKP Sulawesi Utara dan sampel adalah auditor yang bekerja pada BPKP Sulawesi Utara. Dengan teknik sampling yang digunakan nonprobability sampling dengan teknik purposive sampling.

Tempat dan Waktu Penelitian. Peneliti melakukan penelitian pada Badan Pengawasan Keuangan dan Pembangunan Sulawesi Utara. Penelitian dilakukan pada bulan Mei sampai dengan selesai.

\section{Definisi Operasional}

a. Kompetensi $\left(\mathrm{X}_{1}\right)$, adalah kemampuan auditor mempunyai pengetahuan umum secara luas serta keahlian khusus untuk melakukan audit.

b. Objektivitas $\left(\mathrm{X}_{2}\right)$, merupakan tindakan auditor yang adil, tidak dipengaruhi dengan hubungan kerjasama serta tidak memihak kepada siapapun.

c. Tekanan anggaran waktu $\left(\mathrm{X}_{3}\right)$, merupakan keadaan yang mengharuskan auditor menggunakan waktu semaksimal mungkin dari waktu yang telah dianggarkan atau batasan waktu yang ketat dan kaku.

d. Kualitas hasil audit (Y), kualitas kinerja auditor yang dilihat dari laporan hasil pemeriksaan handal berdasarkan standar yang ditetapkan.

\section{Metode Pengumpulan Data}

Jenis Data. Data dalam penelitian ini yakni, data kualitatif (skala likert) yang akan diubah menjadi data kuantitatif.

Sumber Data. Sumber data penelitian didapat langsung dari objek penelitian (data primer), berupa wawancara yang dilakukan oleh peneliti di BPKP dan pemberian kuesioner tentang pengaruh kompetensi, objektivitas, dan tekanan anggaran waktu terhadap kualitas hasil audit yang berisi beberapa pernyataan untuk setiap variabel yang nantinya diedarkan kepada Auditor BPKP Perwakilan Sulawesi Utara. 


\section{Pengujian Kualitas Data}

1. Uji validitas. Untuk mengukur sah atau valid tidaknya suatu kuesioner.

2. Uji Reliabilitas. Untuk mengukur suatu kuesioner apakah sudah realibel atau tidak.

\section{Pengujian Asumsi Klasik}

1. Uji Normalitas. Uji normalitas untuk menguji data penelitian telah berdistribusi normal.

2. Uji Heteroskedastisitas. Uji heteroskedastisitas untuk menguji apakah dalam regresi terjadi ketidaksamaan varian.

3. Uji Multikolinearitas. Uji multikolinearitas untuk menguji terdapat variabel independen yang saling berhubungan kuat satu dengan yang lain.

\section{Metode Analisis}

1. Analisis Regresi Linear Berganda. Dajan (2001:81) regresi linear berganda merupakan bentuk secara teoritis, variabel tidak bebas yang akan diteliti merupakan kecenderungan hubungan yang linear terhadap masing-masing variabel bebasnya.

2. Koefisien Determinasi. Analisis koefisien determinasi digunakan untuk besarnya pengaruh variabel bebas $(\mathrm{X})$ terhadap variabel terikat $(\mathrm{Y})$.

3. Pengujian Hipotesis (Uji t). Sugiyono (2014:194) uji t digunakan melihat kontribusi dan pengaruh secara parsial dari setiap variabel independen terhadap variabel dependen.

\section{HASIL PENELITIAN DAN PEMBAHASAN}

\subsection{Hasil Penelitian}

Tabel 1 menunjukkan hasil penelitian yang menggambarkan kondisi-kondisi umum responden dalam penelitian ini.

Tabel 1. Deskripsi Umum Responden

\begin{tabular}{lcc}
\hline \multicolumn{1}{c}{ Keterangan } & Jumlah & Persentasi \\
\hline Jumlah Responden & & \\
Kuesioner yang disebar & 55 & $100 \%$ \\
Kuesioner yang tidak kembali & 7 & $13 \%$ \\
Kuesioner yang tidak lengkap & 3 & 5 \\
Kuesioner yang digunakan & 45 & $82 \%$ \\
Jenis Kelamin & & \\
Laki-laki & 33 & $73 \%$ \\
Perempuan & 12 & $27 \%$ \\
Usia & & \\
$<25$ tahun & & $2 \%$ \\
26-35 tahun & 1 & $73 \%$ \\
36-55 tahun & 33 & $16 \%$ \\
$>55$ tahun & 7 & $9 \%$ \\
Tingkat Pendidikan & 4 & \\
Strata 1 (S1) & & $93 \%$ \\
Strata (S2) & & $7 \%$ \\
Strata (S3) & 42 & 0 \\
Pengalaman Auditor & 3 & \\
$<1$ tahun & - & 0 \\
1-5 tahun & & $27 \%$ \\
6-10 tahun & & $51 \%$ \\
\hline 10 tahun & - &
\end{tabular}

Sumber: Pengolahan Data, 2018 
Uji Kualitas Data

a. Uji Validitas

Tabel 2. Uji Validitas

\begin{tabular}{|c|c|c|c|c|}
\hline Variabel & Pernyataan & r-Hitung & r-Tabel & Keterangan \\
\hline \multirow{10}{*}{ Kompetensi (X1) } & 1 & 0,591 & 0,2940 & Valid \\
\hline & 2 & 0,534 & 0,2940 & Valid \\
\hline & 3 & 0,804 & 0,2940 & Valid \\
\hline & 4 & 0,651 & 0,2940 & Valid \\
\hline & 5 & 0,706 & 0,2940 & Valid \\
\hline & 6 & 0,814 & 0,2940 & Valid \\
\hline & 7 & 0,781 & 0,2940 & Valid \\
\hline & 8 & 0,640 & 0,2940 & Valid \\
\hline & 9 & 0,744 & 0,2940 & Valid \\
\hline & 10 & 0,694 & 0,2940 & Valid \\
\hline \multirow[t]{8}{*}{ Objektivitas (X2) } & 1 & 0,615 & 0,2940 & Valid \\
\hline & 2 & 0,832 & 0,2940 & Valid \\
\hline & 3 & 0,828 & 0,2940 & Valid \\
\hline & 4 & 0,718 & 0,2940 & Valid \\
\hline & 5 & 0,745 & 0,2940 & Valid \\
\hline & 6 & 0,813 & 0,2940 & Valid \\
\hline & 7 & 0,786 & 0,2940 & Valid \\
\hline & 8 & 0,731 & 0,2940 & Valid \\
\hline \multirow[t]{5}{*}{ Tekanan Anggaran Waktu (X3) } & 1 & 0,767 & 0,2940 & Valid \\
\hline & 2 & 0,428 & 0,2940 & Valid \\
\hline & 3 & 0,894 & 0,2940 & Valid \\
\hline & 4 & 0,801 & 0,2940 & Valid \\
\hline & 5 & 0,826 & 0,2940 & Valid \\
\hline \multirow[t]{10}{*}{ Kualitas Hasil Audit (Y) } & 1 & 0,845 & 0,2940 & Valid \\
\hline & 2 & 0,850 & 0,2940 & Valid \\
\hline & 3 & 0,804 & 0,2940 & Valid \\
\hline & 4 & 0,815 & 0,2940 & Valid \\
\hline & 5 & 0,877 & 0,2940 & Valid \\
\hline & 6 & 0,739 & 0,2940 & Valid \\
\hline & 7 & 0,470 & 0,2940 & Valid \\
\hline & 8 & 0,681 & 0,2940 & Valid \\
\hline & 9 & 0,728 & 0,2940 & Valid \\
\hline & 10 & 0,846 & 0,2940 & Valid \\
\hline
\end{tabular}

Sumber: Data hasil olahan SPSS, 2018

b. Uji Reliabilitas

Tabel 3. Uji Reliabilitas

\begin{tabular}{lccc}
\hline \multicolumn{1}{c}{ Variabel } & Item & Nilai Cronbach Alpha & Keterangan \\
\hline Kompetensi & 10 & 0,916 & Reliabilitas \\
Objektivitas & 8 & 0,809 & Reliabilitas \\
Tekanan Anggaran Waktu & 5 & 0,889 & Reliabilitas \\
Kualitas Hasil Audit & 10 & 0,882 & Reliabilitas \\
\hline
\end{tabular}

Sumber: Data hasil olahan SPSS, 2018 
Uji Asumsi Klasik

a. Uji Normalitas

Tabel 4. Uji Normalitas - One-Sample Kolmogorov-Smirnov Test

\begin{tabular}{llr}
\hline N & & \multicolumn{2}{c}{ Unstandardized Residual } \\
Normal Parameters ${ }^{\text {a,b }}$ & Mean & 45 \\
& Std. Deviation & $0 \mathrm{E}-7$ \\
& Absolute & 2.74252186 \\
Most Extreme Differences & Positive & 0.136 \\
& Negative & 0.136 \\
Kolmogorov-Smirnov Z & & -0.060 \\
Asymp. Sig. (2-tailed) & & 0.912 \\
& & 0.376 \\
\hline
\end{tabular}

a. Test distribution is Normal.

b. Calculated from data.

Sumber: Data hasil olahan SPSS, 2018

Hasil uji menunjukan nilai signifikansi adalah sebesar $0,376>0,05$ berarti nilai residual berdistribusi normal.

b. Uji Multikolonieritas

Tabel 5. Uji Multikolonieritas- Coefficients ${ }^{\mathrm{a}}$

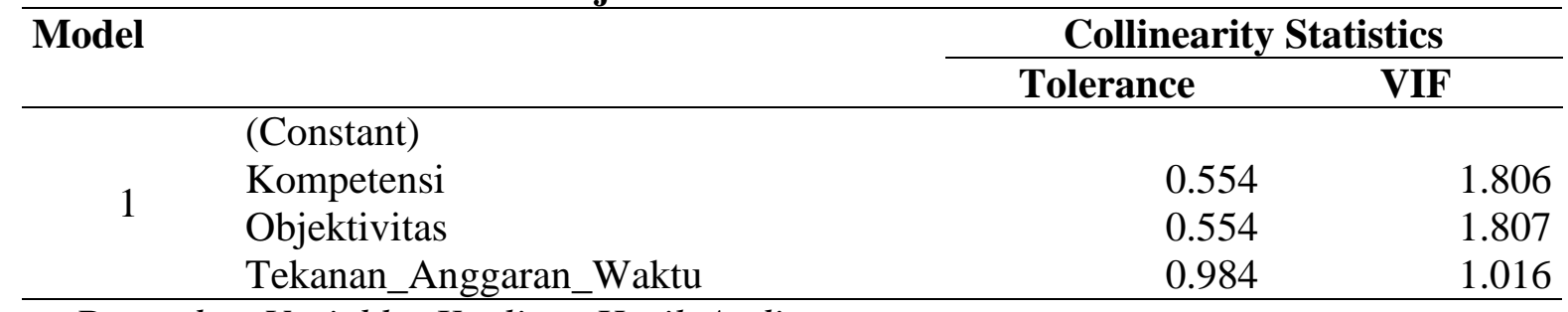

a. Dependent Variable: Kualitas_Hasil_Audit

Sumber: Data hasil olahan SPSS, 2018

Hasil uji multikolinearitas diperoleh Kompetensi nilai tolerance 0,554 $>0,1$ dan nilai VIF $1,806<10$, Objektivitas nilai tolerance 0,554 > 0,1 dan nilai VIF 1,807 < 10, dan Tekanan anggaran waktu $0,984>0,1$ dan nilai VIF $1,016<10$. Menunjukan tidak terjadi multikolinearitas.

c. Uji Heteroskedastisitas

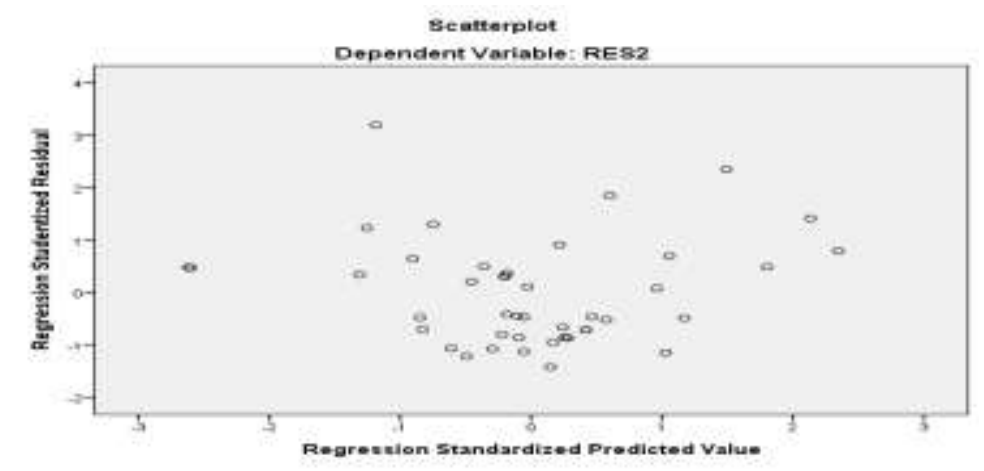

Gambar 1. Hasil Uji Heteroskedastisitas - Uji Scatterplot Sumber: Data hasil olahan SPSS, 2018 
Berdasarkan output scatterplot, tidak terjadi heteroskedastisitas dilihat dari titik yang menyebar dan tidak berpola.

\section{Koefisien Determinasi $\left(\mathbf{R}^{2}\right)$}

Tabel 7. Koefisien Determinasi $\left(\mathbf{R}^{2}\right)$

\begin{tabular}{ccrrr}
\hline Model & R & R Square & Adjusted R Square & Std. Error of the Estimate \\
\hline 1 & $0.712^{\mathrm{a}}$ & 0.507 & 0.471 & 2.841 \\
\hline
\end{tabular}

a. Predictors: (Constant), Tekanan_Anggaran_Waktu, Kompetensi, Objektivitas

b. Dependent Variable: Kualitas_Hasil_Audit

Sumber: Data hasil olahan SPSS, 2018

Nilai adjusted sebesar 0,471, menjelaskan kemampuan variabel independen atas variabel dependen sebesar 47,1\% sedangkan 52,9\% lainnya dijelaskan oleh faktor-faktor lain.

\section{Uji Hipotesis}

a. Uji t (Uji Parsial)

Tabel 6. Uji Regresi Linear Berganda

\begin{tabular}{|c|c|c|c|c|c|c|}
\hline \multirow{2}{*}{\multicolumn{2}{|c|}{ Model }} & \multicolumn{2}{|c|}{$\begin{array}{l}\text { Unstandardized } \\
\text { Coefficients }\end{array}$} & \multirow{2}{*}{$\begin{array}{c}\begin{array}{c}\text { Standardized } \\
\text { Coefficients }\end{array} \\
\text { Beta }\end{array}$} & \multirow[t]{2}{*}{$\mathbf{t}$} & \multirow[t]{2}{*}{ Sig. } \\
\hline & & B & Std Error & & & \\
\hline & (Constant) & 8.979 & 6.276 & & 1.431 & 0.160 \\
\hline & Kompetensi & 0.404 & 0.165 & 0.360 & 2.440 & 0.019 \\
\hline & Objektivitas & 0.499 & 0.175 & 0.419 & 2.845 & 0.007 \\
\hline & Tekanan Anggaran Waktu & -0.002 & 0.117 & -0.002 & -0.021 & 0.983 \\
\hline
\end{tabular}

a. Dependent Variable: Kualitas_Hasil_Audit

koefisien regresi nilai penurunan atau peningkatan

Sumber: Data hasil olahan SPSS, 2018

Dari hasil uji didapatkan model persamaan regresi linear berganda untuk penelitian ini, yaitu:

$$
Y=8.979+0,404 X 1+0,499 X 2-0,002 X 3+e
$$

Hasil interpretasi sebagai berikut:

1. Konstanta $(\alpha)$ sebesar 8,979, menunjukan jika tidak terdapat nilai kompetensi (X1), objektivitas (X2), dan tekanan anggaran waktu (X3) atau sama dengan nol maka kualitas hasil audit (Y) nilainya adalah 8,979.

2. Koefisien regresi $\left(\beta_{1}\right)$ untuk kompetensi bernilai positif sebesar 0,404 artinya pengaruh kompetensi terhadap kualitas hasil audit adalah bersifat positif.

3. Koefisien regresi $\left(\beta_{2}\right)$ untuk objektivitas bernilai positif sebesar 0,499 artinya pengaruh kompetensi terhadap kualitas hasil audit adalah bersifat positif.

4. Koefisien regresi $\left(\beta_{3}\right)$ untuk tekanan anggaran waktu bernilai negatif sebesar $-0,002$ artinya pengaruh tekanan anggaran waktu terhadap kualitas hasil audit adalah bersifat negatif.

Hasil analisis regresi menunjukan nilai t-hit kompetensi sebesar 2,440> 2,019 dan nilai sig $0,019<0,05$, maka $\mathrm{H}_{\mathrm{a} 1}$ diterima dan $\mathrm{H}_{01}$ ditolak, berarti kompetensi berpengaruh signifikan terhadap kualitas hasil audit, nilai t-hit objektivitas sebesar 2,845> 2.019 dan nilai sig 0,007 $<0,05$, maka $\mathrm{H}_{\mathrm{a} 1}$ diterima dan $\mathrm{H}_{01}$ ditolak, berarti objektivitas berpengaruh signifikan terhadap kualitas hasil audit, dan nilai t-hit tekanan anggaran waktu sebesar $-0,021<2.019$ dan nilai sig 0,983 >0,05, berarti tekanan anggaran waktu tidak berpengaruh signifikan terhadap kualitas hasil audit. 
b. Uji F (Uji Simultan)

Tabel 8. Uji F - ANOVA ${ }^{\mathrm{a}}$

\begin{tabular}{llrrrrr}
\hline \multicolumn{1}{c}{ Model } & Sum of Squares & Df & Mean Square & F & Sig. \\
\hline & Regression & 340.168 & 3 & 113.389 & 14.048 & $.000^{\mathrm{b}}$ \\
1 & Residual & 330.943 & 41 & 8.072 & & \\
Total & 671.111 & 44 & & & \\
\hline
\end{tabular}

a. Dependent Variable: Kualitas_Hasil_Audit

b. Predictors: (Constant), Tekanan_Anggaran_Waktu, Kompetensi, Objektivitas

Sumber: Data hasil olahan SPSS, 2018

Hasil uji F, menunjukan nilai F-hit. 14,048 > 2,830 dan nilai sig. 0,000 < 0,05. Berarti kompetensi, objektivitas, dan tekanan anggaran waktu berpengaruh signifikan terhadap kualitas hasil audit.

\subsection{Pembahasan}

Pengaruh Kompetensi terhadap Kualitas Hasil Audit. Berdasarkan hasil pengujian yang dilakukan diketahui bahwa kompetensi memiliki nilai $t_{\text {hit }} 2,440<2,019$ dan nilai sig $0,019<0,05$ maka bedasarkan hipotesis penelitian $\mathrm{H}_{\mathrm{a} 1}$ diterima dan $\mathrm{H}_{01}$ ditolak. Artinya kompetensi berpengaruh signifikan terhadap kualitas hasil audit karena kompetensi merupakan hal yang sangat penting dan yang harus terus ditingkatkan oleh auditor BPKP Sulawesi Utara. Praktek profesional sekarang ini tidak lagi menonjolkan gelar akademik, melainkan gelar keahlian. Gelar akademik cenderung ke konsep teoritis sedang gelar keahlian berarti dipandang telah memiliki kompetensi, keahlian, dan kemapanan dalam bertindak. Kompetensi auditor BPKP ditingkatkan melalui diklat / workshop dan pendidikan yang ditempuh. Hasil penelitian ini mendukung hasil penelitian yang dilakukan oleh Harahap (2015), Yusuf (2014) dan Shintya dkk (2016) menunjukkan bahwa kompetensi mempunyai hubungan searah dan berpengaruh signifikan terhadap kualitas hasil audit karena kompetensi merupakan hal yang harus dimiliki oleh seorang auditor dalam melaksanakan audit untuk menghasilkan laporan audit yang baik dan benar.

Pengaruh Objektivitas terhadap kualitas hasil audit. Berdasarkan hasil pengujian yang dilakukan diketahui bahwa objektivitas memiliki nilai $t_{\text {hit }} 2,845>2,019$ dan nilai sig $0,007<0,05$ dengan demikian maka bedasarkan hipotesis penelitian $\mathrm{H}_{\mathrm{a} 2}$ diterima dan $\mathrm{H}_{02}$ ditolak. Artinya objektivitas berpengaruh signifikan terhadap kualitas hasil audit karena objektivitas adalah salah satu yang harus dijaga oleh auditor BPKP Sulawesi Utara untuk menghasilkan laporan hasil audit yang baik dan dapat dipercaya. Seorang auditor yang objektif memberikan laporan audit dengan sikap yang tidak memihak, tidak bias, dan menghindari konflik kepentingan. Auditor BPKP melakukan tugasnya dengan cepat dan ketepatan serta mempertahan objektivitasnya dalam melaksanakan tugas sebagai auditor internal pemerintah. Hasil penelitian ini mendukung penelitian yang dilakukan oleh Harahap (2015), Adelia (2016) dan Yusuf (2014) menunjukkan bahwa objektivitas mempunyai hubungan searah dan berpengaruh signifikan terhadap kualitas hasil audit karena objektivitas merupakan hal yang harus dimiliki dan dijaga dalam profesi akuntan atau seorang auditor dalam melaksanakan pemeriksaan.

Pengaruh Tekanan Anggaran Waktu terhadap kualitas hasil audit. Berdasarkan hasil pengujian yang dilakukan diketahui bahwa tekanan anggaran waktu memiliki nilai $t_{\text {hit }}$ $0,021<2,019$ dan nilai sig 0,983>0,05 dengan demikian maka berdasarkan hipotesis penelitian $\mathrm{H}_{\mathrm{a} 3}$ ditolak dan $\mathrm{H}_{03}$ diterima. Artinya tekanan anggaran waktu tidak berpengaruh signifikan terhadap kualitas hasil audit. Tekanan anggaran waktu memiliki hubungan berlawanan arah terhadap kualitas hasil audit, dimana semakin ketat tekanan anggaran waktu 
maka kualitas hasil audit semakin menurun (De Zoort dan Lord 1997). Teori ini tidak terbukti pada kinerja auditor BPKP, karena tekanan anggaran waktu sama sekali tidak mempengaruhi akan kualitas hasil audit yang diperiksa oleh auditor BPKP, karena meskipun auditor BPKP Sulawesi Utara bekerja dalam alokasi waktu yang ketat, kualitas hasil auditnya tetap dipertahankan. Hasil penelitian ini mendukung hasil penelitian yang dilakukan oleh Robertus (2016), Rizal (2016), dan Zam (2015) menunjukkan bahwa tekanan anggaran waktu mempunyai hubungan berlawanan arah dan tidak berpengaruh signifikan terhadap kualitas hasil audit. Pengaruh yang tidak signifikan disebabkan karena tekanan anggaran waktu bukan merupakan penentu dari penurunan kualitas hasil audit.

\section{KESIMPULAN DAN SARAN}

\subsection{Kesimpulan}

1. Kompetensi mempunyai hubungan searah dan signifikan terhadap kualitas hasil audit, terbukti dengan hasil uji hipotesis parsial (uji t) yang telah di lakukan. Dengan demikian, hipotesis pertama $\left(\mathrm{H}_{\mathrm{a} 1}\right)$ diterima, yaitu kompetensi berpengaruh signifikan terhadap kualitas hasil audit.

2. Objektivitas mempunyai hubungan searah dan signifikan terhadap kualitas hasil audit, terbukti dengan hasil uji hipotesis parsial (uji t) yang telah di lakukan. Dengan demikian, hipotesis kedua $\left(\mathrm{H}_{\mathrm{a} 2}\right)$ diterima, yaitu objektivitas berpengaruh signifikan terhadap kualitas hasil audit.

3. Tekanan anggaran waktu mempunyai hubungan berlawanan arah dan tidak signifikan terhadap kualitas hasil audit, terbukti dengan hasil uji hipotesis parsial (uji t) yang telah di lakukan. Dengan demikian, hipotesis kedua $\left(\mathrm{H}_{\mathrm{a} 3}\right)$ ditolak, yaitu tekanan anggaran waktu tidak berpengaruh signifikan terhadap kualitas hasil audit.

\subsection{Saran}

Adapun saran dari penelitian ini adalah : mengingat kompetensi dan objektivitas merupakan variabel yang dominan dalam mempengaruhi kualitas hasil audit, sebaiknya auditor terus meningkatkan kompetensi yang dimiliki baik dari mutu personal, pengetahuan, dan keahlian khusus yang dimilikinya dan juga terus mempertahankan objektivitas sebagai seorang auditor dalam memberikan jasa atau melaksanakan tugas yang diberikan. Sedangkan, tekanan anggaran waktu tidak mempengaruhi kualitas hasil audit dari auditor, maka diharapkan kedepannya terus mempertahankan hal ini supaya walaupun bekerja dibawah tekanan waktu yang diberikan hasil audit tetap memiliki kualitas yang baik.

Dalam penelitian ini peneliti mengambil tiga faktor yang memepengaruhi kualitas hasil audit, yaitu kompetensi, objektivitas, dan tekanan anggaran waktu yang dijadikan sebagai variabel independen dan kualitas hasil audit sebagai variabel dependen. Dalam penelitian selanjutnya perlu dilakukan pengembangan variabel-variabel lainnya untuk memperkaya faktor-faktor yang mempengaruhi kualitas hasil audit sebagai bentuk pengembangan dari penelitian dan pengembangan pengetahuan.

\section{DAFTAR PUSTAKA}

Adelia, Fildzah. 2016. Pengaruh Objektivitas, Pengalaman, dan Tekanan Anggaran Waktu terhadap Kualitas Audit. Jurnal. Fakultas Ekonomi dan Bisnis Universitas Hasanuddin. Makasar.

Amir Abadi Jusuf. 2013. Jasa Auditan dan Assurance. Buku 1,Jakarta:Salemba Empat.

Arens, Alvin. A dan Loebbecke James .K. 2003. Auditing (Pendekatan Terpadu). Buku I. Edisi Indonesia. Jakarta: Salemba Empat.

Arens, A., Alvin, Randal J., Elder, Mark S., dan Amin Abadi Jusuf. 2013. Jasa Auditan dan Assurance. Buku 1. Jakarta: Salemba Empat. 
De Zoort, F. Todd., and Alan, T. Lord. 1997. A Review and Synthesis of Pressure Effects Research in Accounting. Journal of Accounting Literature Vol. 16 pg. 28, 58 pgs.

Fonda, Jean, Ausella. 2014. Pengaruh Tekanan Anggaran Waktu, Tipe Kepribadian Auditor, Independensi, dan Kompetensi Terhadap Kualitas Audit. Skripsi. Fakultas Ekonomi dan Bisnis. Universitas Diponegoro. Semarang.

Harahap, Lukman. 2015 Pengaruh Kompetensi, Independensi, Objektivitas, dan Sensitivitas Etika Provesi Terhadap Kualitas Hasil Audit (Studi Kasus Pada Auditor BPKP Daerah Istimewa Yogyakarta). Skripsi. Universitas Negeri Yogyakarta. Yogyakarta.

Martani. 2012. Akuntansi Keuangan Menengah Berbasis PSAK. Jakarta: Salemba Empat.

Mulyadi. 2013. Sistem Akuntansi. Jakarta: Salemba Empat. 2014. Sistem Akuntansi. Yogyakarta: Salemba Empat.

Rizal, Noviansyah dan Liyundira, Fetri Setyo. 2016. Pengaruh Tekanan Waktu dan Independensi Terhadap Kualitas Audit. Jurnal Ilmu Ekonomi. STIE Widya Gama Lumajang.

Sososutikno, Christina. 2003. Hubungan Tekanan Anggaran Waktu dengan Perilaku Disfungsional serta Pengaruhnya terhadap Kualitas Audit. Simposium Nasional Akuntansi VI. Surabaya.

Shintya, Agneus., Nuryatno, Muhammad., Oktaviani, Aulia, Ayu. 2016. Pengaruh Kompetensi, Independensi, dan Tekanan Anggaran Waktu Tehadap Kualitas Audit. Skripsi. Fakultas Ekonomi dan Bisnis Universitas Trisakti Jakarta.

Sugiyono. 2014. Metode Penelitian Kuantitatif, Kualitatif, dan Kombinasi (Mixed Methods). Bandung : Alfabeta.

Widodo, Robertus, Aryo, Kusumo. 2016. Pengaruh Kompetensi, Tingkat Pendidikan Auditor dan Time Budget Pressure Terhadap Kualitas Hasil Audit. Jurnal Akuntansi. Fakultas Ekonomi dan Bisnis. Universitas Katolik.

Yusuf, M. 2014. Pengaruh Kompetensi, Objektivitas, dan Integritas Auditor Terhadap Kualitas Hasil Kerja (Studi Empiris pada Auditor BPKP Provinsi Riau). Skripsi. Program Studi Akuntansi Fakultas Ekonomi Universitas Negeri Padang.

Zam, Dewi, Rosari Putri. 2015. Pengaruh Tekanan Anggaran Waktu (Time Budget Pressure), Fee Audit dan Independensi Auditor Terhadap Kualitas Audit. Jurnal. Fakultas Ekonomi dan Bisnis. Universitas Telkom. 